\title{
Promoting Balanced Nutrition Guidelines among adolescent: evaluation of the nutrition posters and stickers as a nutrition education media
}

\author{
E Emilia $^{1,3}$, R Mulyana $^{2}$, R Rosmiati $^{1}$ \\ ${ }^{1}$ Department of Family Welfare Education, Faculty of Engineering, State University of Medan, \\ Jl. Willem Iskandar, Psr V, Medan, 20221, Indonesia \\ ${ }^{2}$ Department of Building Engineering Education, Faculty of Engineering, State University of \\ Medan, Jl. Willem Iskandar, Psr V, Medan, 20221, Indonesia
}

\begin{abstract}
Nutrition education media is one of the solutions to improve adolescent nutritional behavior. The objectives of this research were to develop the nutrition poster and sticker regarding Balanced Nutrition Guidelines for adolescents and do the pilot test to analyze the nutritional behavior of junior high school (SMP) students. The study design was descriptive quantitative-qualitative study and conducted from March 2015-November 2016. The pilot test conducted at three SMP in Medan city. Fourteen dietary guideline messages have been designed into the nutrition posters and stickers as a nutrition education media for adolescents. The nutrition posters and stickers design have been revised based on the suggestions from experts (education, nutrition, and media experts) and FGD results. Pilot test showed that nutrition posters and stickers could increase nutritional behavior of subjects. The results indicate that the nutrition posters and stickers can be used as a nutrition education media to promote Balanced Nutrition Guidelines.
\end{abstract}

\section{Introduction}

In Indonesia, malnutrition in each age group is still a significant public health problem, including adolescent. Data from national basic health research in 2013 showed that the proportion of stunting, wasting, overweight and obesity at $13-15$ years old is $35.1 \%, 11.1 \%, 8.3 \%$, and $2.5 \%$, respectively. Also, the proportion of anemia is $21.7 \%$ at 5-14 years old [1]. Approximately 2.5 million girls under 16 years give birth each year in developing regions [2]. In Indonesia, 1.97\% of adolescents (at 15-19 years old) have a first pregnancy [1].

The adolescent period is a critical phase in thelifespan. Adolescents experience rapid growth and increaseenergy, protein, vitamin, and mineral requirements. The nutritional status of adolescents requires close monitoring because they represent the next generation of parents [3]. Unhealthful diets during this critical time may be linked to dramatic changes in body shape, preoccupation with physical appearance, increased autonomy in decision-making, and a growing desire to conform to social pressures [4]. Undernutrition will lower resistance to disease, increased morbidity and stunting, lower level of intelligence and lowered productivity [5]. Obesity in an adolescentis associated with degenerative diseases and obesity in adulthood [6], [7]. Anemia among adolescent girls will bring negative consequences on growth, school performance, morbidity, and reproductive performance. 
Some adolescents are unaware that their current eating habits will impact their health status in the future [8]. These problems are contrary to the guidelines for balanced nutrition. Low nutritional knowledge and attitudes influence low nutrition practices [9]. In general, to be able to understand and apply the Dietary Guidelines recommendations for healthful eating practices, some basic understanding of nutrition is necessary [10]. The Guideline for Balanced Nutrition socialization program is a community nutrition education program that can provide many benefits. School-age children including adolescent are one of the targets for the implementation of the Guidelines for Balanced Nutrition. School groups are groups that readily accept nutritional education programs in their schools [11].

Nutrition education programmes are designed to improve nutrition knowledge, with the aim of supporting healthy dietary intake within the community or a specific target population [12], [13]. Proper nutrition knowledge is useful in improving dietary habits, and adolescents are empowered when they have the necessary nutrition knowledge and skills needed to make healthy lifestyle choices[14], [15].

Nutrition education media is part of the supporting elements for the success of nutrition education, especially for school children. An exciting educational media can increase children's curiosity about the content of the media itself. Education using media also makes it easier for material providers to deliver material. Also, the media can also simplify material both in the form of pictures and sounds that can be easily accepted by children. Nutrition educators need to design messages that attract attention, make sense, and help to encourage change in what are often entrenched attitudes and behaviors in the target audience [16]. The research will use ICT-based child nutrition education media by Emilia [17]. This study aimed to develop the nutrition posters and stickers regarding dietary guidelines for adolescents and do the pilot test of the nutrition posters and stickers to analyze the nutritional behavior of junior high school students

\section{Methods}

\subsection{Design, location and time}

The study design was descriptive quantitative-qualitative study and conducted from March 2015 until November 2016. The pilot test conducted in three junior high schools in Medan city such as SMPN 7 Medan, SMP Al Ulum Medan, and SMPN 8 Medan.

\subsection{Sampling}

The subjects for the pilot test were the student ( $8^{\text {th }}$ grade) of 3 selected schools which was selected by stratified random sampling. The sample size was 49 persons.

\subsection{Data type and collection}

Nutritional messages developed into the nutrition posters and stickers based on low nutritional knowledge score of adolescents in previous studies and literature studies. The media design was validated by experts (nutrition, educational, and media experts) and focus group discussions (FGDs). The nutrition posters and stickers design have been revised based on the suggestions from experts and FGD results. Furthermore, a pilot test was conducted to junior high school students for one month. The pilot test data is the nutrition behavior of an adolescent. The data consisted of pretest and post-test data, i.e., data before and after the socialization of the nutrition posters and stickers.

\subsection{Data analysis}

The collected data is processed statistically descriptive. The test used is Wilcoxon to analyze the difference in the increase of nutritional behavior before and after given the socialization of the nutrition posters and stickers.

\section{Results and discussion}




\subsection{The nutrition posters and stickers development}

Poster and stickers have been used for a long time in health and nutrition promotion and target a wide range of issues such as food choices [18], exercise [19], and smoking [20]. Posters are twodimensional visual materials which can be used without place constraints. Many sectors make use of posters prepared on scientific principles in order to give information, raise awareness and convince audiences [21]. The educational effectiveness of a poster is determined by its contents, design and readability level [22].

Fourteen dietary guideline messages that would be designed into the nutrition poster and sticker were 1) Eat a variety of foods; 2) Consume high fiber foods that eat plenty of vegetables and fruits; 3) Eat breakfast every day; 4) Increase knowledge about nutrition and reproduction health relationship; 5) Consume iron-rich foods; 6) Consume calcium-rich foods; 7) Eat a variety of staple foods; 8) Limit consumption of sweet, salty and fatty foods; 9) Limit consumption of fast foods; 10) Read the labels of packaged foods; 11) Consume safe foods; 12) Do physical activity regularly and maintain a normal weight; 13) No smoking, alcoholic beverages, and drugs; 14) Drink 8 glasses of water a day.

All the messages were based on Indonesia Balanced Nutrition Guidelines. The nutrition posters and stickers design have several aspects into consideration, specifically messages and images should be simple and easy to understand by the adolescent. Also, messages consist of definition, impact, and explanation of the healthylifestyle concept for adolescents. A review by Jenner et al.[23] concluded that the most effective messages for health promotion behaviors should be framedregarding gains rather than losses for the individual. The use of repeated minimal fear appeals has their place. Posters that simply convey training messages are not effective persuaders. Messages with more intense or graphic content do arouse more audience fear and fear appeals can be persuasive [16].

\subsection{Validation of the nutrition posters and stickers}

The validation process of the nutrition posters and stickers used expert validation and focus group discussions (FGD). Expert validation consists of education, nutrition, and media experts to obtain better nutrition posters and sticker according to the proficiency of each expert. Experts also assess the media appearances based on the suitability of color, image and text display on the material, the standard language used, ease understanding language used, and conformity of the message content with the expected definition. FGDs were conducted on the target groups of students and school staffs such as teachers, school medical room, and canteen managers.

3.2.1. Education expert. Overall, the sticker media appearance regarding color, text and the proportion of the imagewas good. Some stickers need to add a real picture of the health risks when do not follow the messages. For example, the message "No smoking, alcoholic beverages, and drugs" add pictures of smoking people have lung cancer. Media posters as a whole have delivered the message well, but need to add the impact when they follow or not the message, so the readers can immediately grasp the meaning of the message. Some messages need to be changed the font color because the color degradation is too homogenous, so it is difficult to read. Moreover, some messages need to be simplifiedfor better understanding by the target.

3.2.2. Nutrition expert. Overall, the media have delivered the messages well. However, there was an error in displaying the picture on the message "Eat a variety of staple foods." The picture displayed all types of food such as the source of staple foods, protein source foods, vegetables, and fruits. It should be added by the sources of various carbohydrates source foods such as rice, whole grains, and tubers.

3.2.3. Media expert. Overall, the harmony of colors, letters, and visuals was good for sticker media. However, some font size and color of the stickers had to fix to make it more transparent for reading. Moreover, added lines for several stickers to reinforce the messages. Some posters required changes in the color of letters and font size to make it look clearer. For example, the message "limit consumption of fast food" the letters for the message are given a darker color and for the explanation of the message is given a lighter color. 
3.2.4. Focus group discussion (FGD) with students and school staffs. In general, the designed media could be understood by the targets. However, some message content should be used as a more straightforward sentence and more detailed explanation of the nutritional terms. FGDs discussed three aspects i.e. the messages should be simple and easy to understand by the adolescent; the suitability and harmony of the image and letters color; and the overall appearance. The nutrition posters and stickers have been revised based on a suggestion from experts and FGD results (Appendix A).

\subsection{Pilot test of the nutrition posters and stickers}

The pilot test was conducted to analyze how much the nutritional behavior improve, especially the student nutritional knowledge after the media has been socialized. Nutritional knowledge is the subject comprehension related to nutrition matters. It is also a component that related to the attitude of nutrition and health care [13]. The changes on average nutritional knowledge, attitude and practice score of subjects can be seenin Table 1 .

Table 1.The changes onaverage nutritional knowledge, attitude and practice score of pretest and posttest subjects.

\begin{tabular}{lccc}
\hline \multicolumn{1}{c}{ Nutritional messages } & $\begin{array}{c}\text { Knowledge } \\
(\text { mean } \pm \text { SE) }\end{array}$ & $\begin{array}{c}\text { Attitude } \\
(\text { mean } \pm \text { SE) }\end{array}$ & $\begin{array}{c}\text { Practice } \\
(\text { mean } \pm \text { SE) }\end{array}$ \\
\hline Eat a variety of foods & $53.06 \pm 7.78^{* *}$ & $56.12 \pm 5.58^{* *}$ & $65.31 \pm 2.04^{* *}$ \\
$\begin{array}{l}\text { Consume high fiber foods that eat plenty of } \\
\text { vegetables and fruits }\end{array}$ & $29.59 \pm 5.24^{* *}$ & $26.53 \pm 6.37^{* *}$ & $38.01 \pm 4.85^{* *}$ \\
Eat breakfast every day & $26.53 \pm 3.89^{* *}$ & $8.16 \pm 3.95$ & - \\
$\begin{array}{l}\text { Increase knowledge about nutrition and } \\
\text { reproduction health relationship }\end{array}$ & $25.17 \pm 4.29^{* *}$ & $46.94 \pm 7.77^{* *}$ & - \\
Consume iron-rich foods & $37.41 \pm 5.02^{* *}$ & - & - \\
Consume calcium-rich foods & $41.49 \pm 5.01^{* *}$ & - & - \\
Eat a variety of staple foods & $34.69 \pm 4.76^{* *}$ & - & $24.49 \pm 4.58^{* *}$ \\
Limit consumption of sweet, salty and fatty foods & $38.78 \pm 4.16^{* *}$ & - & $22.96 \pm 16.54 * *$ \\
Limit consumption of fast foods & $18.36 \pm 5.59^{* *}$ & $34.69 \pm 7.46^{* * *}$ & $38.77 \pm 5.26^{* *}$ \\
Read the labels of packaged foods & $16.33 \pm 6.74^{*}$ & $24.49 \pm 7.45^{* *}$ & $41.84 \pm 4.08^{* *}$ \\
Consume safe foods & $67.35 \pm 7.37^{* * *}$ & $36.73 \pm 7.54^{* * *}$ & $63.78 \pm 3.72^{* *}$ \\
$\begin{array}{l}\text { Do physical activity regularly and maintain a } \\
\text { normal weight }\end{array}$ & $7.48 \pm 5.26$ & $29.59 \pm 5.03^{* * *}$ & $61.73 \pm 3.86^{* *}$ \\
No smoking, alcoholic beverages, and drugs & $27.55 \pm 5.66^{* *}$ & $2.04 \pm 2.04$ & $22.96 \pm 4.99^{* *}$ \\
Drink 8 glasses of water a day & $29.59 \pm 4.82^{* * *}$ & - & - \\
\hline
\end{tabular}

* statistically significant at $p<0.05 ; * *$ statistically significant at $\mathrm{p}<0.01$

The scorewas based on 30 questions that grouped into 14 dietary guideline messages. It is giving the maximum score of 100 points and the minimum 0 points for each group messages. The grouping of 
questions was carried out to find out which dietary guideline messages can be accepted and understood by the subject after one-month socialization of the nutrition posters and stickers.

Table 1 showed that the average nutritional knowledge score of subjects all dietary guideline messages significantly increased $(\mathrm{p}<0.05)$, except the message "do physical activity regularly and maintain a normal weight." The result indicates that nutrition posters and stickers can be used as a nutrition education media to improve nutritional knowledge. Visual media could effectively simplify complicated topics, increasing performance, and providing better learning. The most influential factors affecting the knowledge-sharing intentions of posters are intrinsic motivational factors such as enjoyment in helping others and knowledge self-efficacy[24]. Some previous studies showed the same result, nutrition education with visual and image media could increase the nutrition knowledge [25].

Nutritional attitude is the ability of the subjects to decide the attitude about balanced nutrition guidelines through 12 questions with the maximum score of 100 points and the minimum score of 0 points. The questions represent nine dietary guideline messages.

Table 1 showed most of the nutritional attitude score of subjects in each dietary guideline messages significantly improve after the socialization of the nutrition posters and stickers $(p<0.01)$. Two of the nine dietary guideline messages did not improve significantly such as the message about "eat breakfast every day" and "no smoking, alcoholic beverages, and drugs".

The scorewas based on ten questions that represent nine dietary guideline messages. Table 1 showed the nutritional practice score of subject significantly improve on all dietary guideline messages after socialization of the nutrition posters and stickers. It shows that the media used has a positive influence on improving the nutritional practice of the subject after passing one-month socialization. The previous study by [26] used posters as nutrition education media in shopping and commuter venues could improve visitor physical activity. Finding results by Stockli et al.[18]in line with this research stated that poster could influence the choice between healthy and unhealthy foods.

Nutrition knowledge and attitudes were significant predictors of dietary quality. A student with greater nutritional knowledge consumed less unhealthy fats and cholesterol[27]. Moreover, a study by Leonard et al.[28]indicates that knowledge about food sources of iron and iron physiology are related to higher dietary iron intake.

\section{Conclusion}

Fourteen dietary guideline messages have been designed into the nutrition posters and stickers as a nutrition education media for adolescents. The nutrition posters and stickers design have been revised based on the suggestions from experts (education, nutrition, and media experts) and FGD results. Pilot test showed that nutrition posters and stickers could increase nutritional behavior of subjects. The results indicate that the nutrition posters and stickers can be used as a nutrition education media to promote Balanced Nutrition Guidelines.

\section{References}

[1] Ministry of Health, "National Basic Health Report," 2013.

[2] S. Neal, Z. Matthews, M. Frost, H. Fogstad, A. V. Camacho, and L. Laski, "Childbearing in adolescents aged 12-15 years in low resource countries: A neglected issue. New estimates from demographic and household surveys in 42 countries," Acta Obstet. Gynecol. Scand., vol. 91, no. 9 , pp. $1114-1118,2012$.

[3] E. W. Evans and C. Lo, "Adolescents: Nutritional Problems of Adolescents," Encycl. Hum. Nutr., vol. 1-4, pp. 14-22, 2012.

[4] J. Stang and M. T. Story, Guidelines for adolescent nutrition services. Minneapolis: Center for Leadership, Education and Training in Maternal and Child Nutrition, Division of Epidemiology and Community Health, School of Public Health, University of Minnesota, 2005.

[5] V. J. B. Matrins et al., "Long-lasting effects of undernutrition," Int. J. Environ. Res. Public Health, vol. 8, no. 6, pp. 1817-1846, 2011.

[6] B. M. Popkin, "The nutrition transition in the developing world," Dev. Policy Rev., vol. 21, no. 5-6, pp. 581-597, 2003. 
[7] J. D. Goldhaber-Fiebert, R. E. Rubinfeld, J. Bhattacharya, T. N. Robinson, and P. H. Wise, "The utility of childhood and adolescent obesity assessment in relation to adult health," Med Decis Mak., vol. 33, no. 2, pp. 163-175, 2013.

[8] J. Stang and M. T. Story, nutritional problem of adolescence in indonesia.pdf. .

[9] E.-S. Choi, N.-R. Shin, E.-I. Jung, H.-R. Park, H.-M. Lee, and K.-H. Song, "A study on nutrition knowledge and dietary behavior of elementary school children in Seoul," Nutr. Res. Pract., vol. 2, no. 4, pp. 308-316, 2008.

[10] A. Worsley, "Nutrition knowledge and food consumption: can nutrition knowledge change food behaviour?," Asia Pac. J. Clin. Nutr., vol. 11, pp. S579-S585, 2002.

[11] R. Rosário et al., "Impact of an intervention through teachers to prevent consumption of low nutrition, energy-dense foods and beverages: a randomized trial," Prev. Med. (Baltim)., vol. 57, no. 1, pp. 20-25, 2013.

[12] S. Kostanjevec, J. Jerman, and V. Koch, "The Effects of Nutrition Education on 6 th graders Knowledge of Nutrition in Nine-year Primary Schools in Slovenia," vol. 7, no. 4, pp. 243-252, 2011.

[13] I. Spronk, C. Kullen, C. Burdon, and H. O. Connor, "Systematic Review Relationship between nutrition knowledge and dietary intake," pp. 1713-1726, 2014.

[14] E. Emilia, "The floating tool measuring knowledge, attitudes and behavior of nutrition in adolescents," Bogor Agricultural University, 2008.

[15] I. R. Contento, P. A. Koch, H. Lee, and A. Calabrese-Barton, "Adolescents demonstrate improvement in obesity risk behaviors after completion of choice, control \& change, a curriculum addressing personal agency and autonomous motivation," J. Am. Diet. Assoc., vol. 110, no. 12, pp. 1830-1839, 2010.

[16] B. J. Wilson, "Designing media messages about health and nutrition: what strategies are most effective?," J. Nutr. Educ. Behav., vol. 39, pp. S13-S19, 2007.

[17] E. Emilia, "Nutrition Education Media Development ICT-based Child Friendly," in Widyakarya National Food and Nutrition X, 2012.

[18] S. Stöckli, A. E. Stämpfli, C. Messner, and T. A. Brunner, "An (un) healthy poster: When environmental cues affect consumers' food choices at vending machines," Appetite, vol. 96, pp. 368-374, 2016.

[19] O. J. Webb and F. F. Eves, "Promoting stair climbing: effects of message specificity and validation," vol. 22, no. 1, pp. 49-57, 2018.

[20] T. J. Brinker et al., "Photoaging smartphone app promoting poster campaign to reduce smoking prevalence in secondary schools: the Smokerface Randomized Trial: design and baseline characteristics," 2016.

[21] O. Akba, R. Güven, G. Cebeci, and S. Battal, "A study on the effects of seat belt posters on drivers," vol. 2, pp. 1002-1007, 2010.

[22] J. E. Miller, "Preparing and presenting effective research posters," Health Serv. Res., vol. 42, no. 1 p1, pp. 311-328, 2007.

[23] E. A. Jenner, F. Jones, B. C. Fletcher, L. Miller, and G. M. Scott, "Hand hygiene posters : motivators or mixed messages ?," pp. 218-225, 2005.

[24] H.-M. Lai and T. T. Chen, "Knowledge sharing in interest online communities: A comparison of posters and lurkers," Comput. Human Behav., vol. 35, pp. 295-306, 2014.

[25] N. P. Hartono, C. S. Wilujeng, and S. Andarini, "Pendidikan Gizi tentang Pengetahuan Pemilihan Jajanan Sehat antara Metode Ceramah dan Metode Komik," Indones. J. Hum. Nutr., vol. 2, no. 2, pp. 76-84, 2015.

[26] J. Kerr, F. Eves, and D. Carroll, "Posters can prompt less active people to use the stairs," no. May, pp. 942-943, 2000.

[27] R. Cooke and A. Papadaki, "Nutrition label use mediates the positive relationship between nutrition knowledge and attitudes towards healthy eating with dietary quality among university students in the UK 5 ," Appetite, vol. 83, pp. 297-303, 2014.

[28] A. J. Leonard, K. A. Chalmers, C. E. Collins, and A. J. Patterson, "The effect of nutrition 


\section{RedWhitepress Global Conferences Series: Sciences and Technology (GCSST), Volume 3, 2020}

knowledge and dietary iron intake on iron status in young women," Appetite, vol. 81, pp. 225$231,2014$.

\section{Acknowledgments}

This research was supported by The Ministries of Research, Technology and Higher Education, Indonesia.

\section{Appendices}

Appendix A

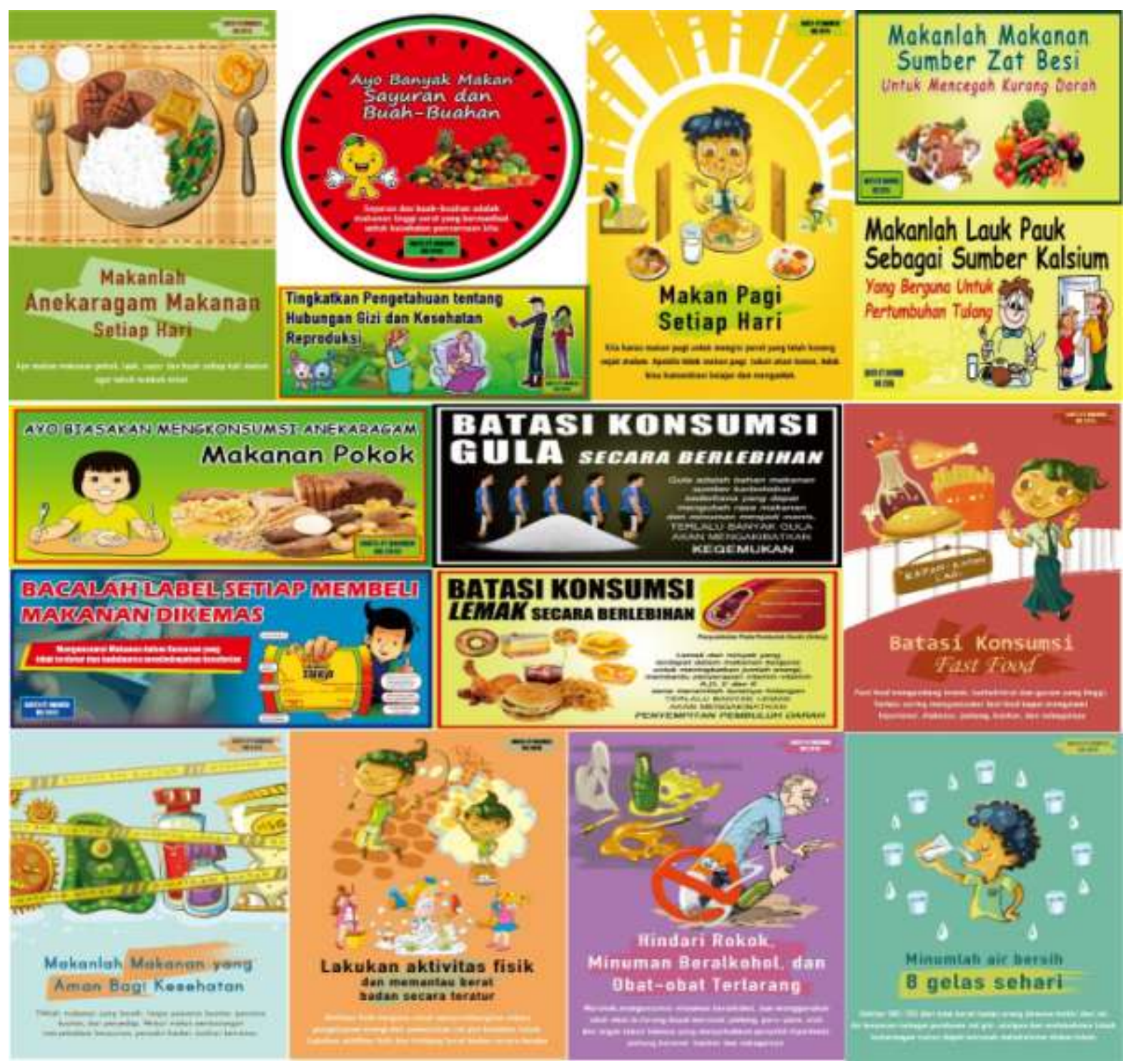

Figure A1. The nutrition posters and stickers design 
Appendix B

Table B1.The average nutritional knowledge score of pretest and posttest subjects.

\begin{tabular}{|c|c|c|c|}
\hline Nutritional messages & $\begin{array}{c}\text { Pretest } \\
(\text { mean } \pm \text { SD })\end{array}$ & $\begin{array}{c}\text { Posttest } \\
(\text { mean } \pm \text { SD })\end{array}$ & $\begin{array}{c}\Delta \\
(\text { mean } \pm \text { SE) }\end{array}$ \\
\hline Eat a variety of foods & $38.77 \pm 7.03$ & $91.84 \pm 3.95$ & $53.06 \pm 7.78 * *$ \\
\hline $\begin{array}{l}\text { Consume high fiber foods that eat plenty of } \\
\text { vegetables and fruits }\end{array}$ & $43.88 \pm 5.58$ & $73.47 \pm 4.39$ & $29.59 \pm 5.24 * *$ \\
\hline Eat breakfast every day & $58.16 \pm 4.46$ & $84.69 \pm 3.32$ & $26.53 \pm 3.89 * *$ \\
\hline $\begin{array}{l}\text { Increase knowledge about nutrition and } \\
\text { reproduction health relationship }\end{array}$ & $63.94 \pm 3.87$ & $89.12 \pm 2.46$ & $25.17 \pm 4.29 * *$ \\
\hline Consume iron-rich foods & $40.82 \pm 3.92$ & $78.23 \pm 3.16$ & $37.41 \pm 5.02 * *$ \\
\hline Consume calcium-rich foods & $39.46 \pm 4.63$ & $80.95 \pm 2.75$ & $41.49 \pm 5.01 * *$ \\
\hline Eat a variety of staple foods & $36.05 \pm 4.11$ & $70.75 \pm 3.45$ & $34.69 \pm 4.76^{* *}$ \\
\hline Limit consumption of sweet, salty and fatty foods & $46.26 \pm 4.22$ & $85.03 \pm 3.08$ & $38.78 \pm 4.16^{* *}$ \\
\hline Limit consumption of fast foods & $81.63 \pm 5.59$ & $100 \pm 0.00$ & $18.36 \pm 5.59 * *$ \\
\hline Read the labels of packaged foods & $73.47 \pm 6.37$ & $89.79 \pm 4.37$ & $16.33 \pm 6.74 *$ \\
\hline Consume safe foods & $26.53 \pm 6.37$ & $93.88 \pm 3.46$ & $67.35 \pm 7.37 * *$ \\
\hline $\begin{array}{l}\text { Do physical activity regularly and maintain a } \\
\text { normal weight }\end{array}$ & $72.11 \pm 4.16$ & $79.59 \pm 3.48$ & $7.48 \pm 5.26$ \\
\hline No smoking, alcoholic beverages, and drugs & $51.02 \pm 4.49$ & $78.57 \pm 4.37$ & $27.55 \pm 5.66^{* *}$ \\
\hline Drink 8 glasses of water a day & $70.41 \pm 4.82$ & $100 \pm 0.00$ & $29.59 \pm 4.82 * *$ \\
\hline
\end{tabular}

* statistically significant at $\mathrm{p}<0.05 ; * *$ statistically significant at $\mathrm{p}<0.01$ 
Table B2.The average nutritional practice score of pretest and posttest subjects.

\begin{tabular}{|c|c|c|c|}
\hline Nutritional messages & $\begin{array}{c}\text { Pretest } \\
(\text { mean } \pm \text { SD })\end{array}$ & $\begin{array}{c}\text { Posttest } \\
(\text { mean } \pm \text { SD })\end{array}$ & $\begin{array}{c}\Delta \\
(\operatorname{mean} \pm \mathrm{SE})\end{array}$ \\
\hline Eat a variety of foods & $2.04 \pm 1.23$ & $67.35 \pm 1.66$ & $65.31 \pm 2.04 * *$ \\
\hline $\begin{array}{l}\text { Consume high fiber foods that eat plenty of } \\
\text { vegetables and fruits }\end{array}$ & $43.37 \pm 3.98$ & $81.38 \pm 2.10$ & $38.01 \pm 4.85^{* *}$ \\
\hline Eat a variety of staple foods & $45.41 \pm 6.08$ & $69.90 \pm 4.25$ & $24.49 \pm 4.58 * *$ \\
\hline $\begin{array}{l}\text { Limit consumption of sweet, salty and fatty } \\
\text { foods }\end{array}$ & $63.77 \pm 16.70$ & $86.73 \pm 2.64$ & $22.96 \pm 16.54 * *$ \\
\hline Limit consumption of fast foods & $49.49 \pm 6.03$ & $88.26 \pm 2.43$ & $38.77 \pm 5.26 * *$ \\
\hline Read the labels of packaged foods & $29.08 \pm 3.88$ & $70.92 \pm 1.68$ & $41.84 \pm 4.08 * *$ \\
\hline Consume safe foods & $27.55 \pm 3.87$ & $91.32 \pm 1.72$ & $63.78 \pm 3.72 * *$ \\
\hline $\begin{array}{l}\text { Do physical activity regularly and maintain a } \\
\text { normal weight }\end{array}$ & $24.49 \pm 3.82$ & $86.22 \pm 2.42$ & $61.73 \pm 3.86^{* *}$ \\
\hline No smoking, alcoholic beverages, and drugs & $51.53 \pm 5.0$ & $74.49 \pm 0.51$ & $22.96 \pm 4.99 * *$ \\
\hline
\end{tabular}

* statistically significant at $\mathrm{p}<0.05$;* statistically significant at $\mathrm{p}<0.01$

Table B3.The average nutritional practice score of pretest and posttest subjects.

\begin{tabular}{|c|c|c|c|}
\hline Nutritional messages & $\begin{array}{c}\text { Pretest } \\
(\text { mean } \pm \text { SD })\end{array}$ & $\begin{array}{c}\text { Posttest } \\
(\text { mean } \pm \text { SD })\end{array}$ & $\begin{array}{c}\Delta \\
(\text { mean } \pm \mathrm{SE})\end{array}$ \\
\hline Eat a variety of foods & $2.04 \pm 1.23$ & $67.35 \pm 1.66$ & $65.31 \pm 2.04 * *$ \\
\hline $\begin{array}{l}\text { Consume high fiber foods that eat plenty of } \\
\text { vegetables and fruits }\end{array}$ & $43.37 \pm 3.98$ & $81.38 \pm 2.10$ & $38.01 \pm 4.85^{* *}$ \\
\hline Eat a variety of staple foods & $45.41 \pm 6.08$ & $69.90 \pm 4.25$ & $24.49 \pm 4.58 * *$ \\
\hline $\begin{array}{l}\text { Limit consumption of sweet, salty and fatty } \\
\text { foods }\end{array}$ & $63.77 \pm 16.70$ & $86.73 \pm 2.64$ & $22.96 \pm 16.54 * *$ \\
\hline Limit consumption of fast foods & $49.49 \pm 6.03$ & $88.26 \pm 2.43$ & $38.77 \pm 5.26^{* *}$ \\
\hline Read the labels of packaged foods & $29.08 \pm 3.88$ & $70.92 \pm 1.68$ & $41.84 \pm 4.08 * *$ \\
\hline Consume safe foods & $27.55 \pm 3.87$ & $91.32 \pm 1.72$ & $63.78 \pm 3.72 * *$ \\
\hline $\begin{array}{l}\text { Do physical activity regularly and maintain a } \\
\text { normal weight }\end{array}$ & $24.49 \pm 3.82$ & $86.22 \pm 2.42$ & $61.73 \pm 3.86^{* *}$ \\
\hline No smoking, alcoholic beverages, and drugs & $51.53 \pm 5.0$ & $74.49 \pm 0.51$ & $22.96 \pm 4.99 * *$ \\
\hline
\end{tabular}

* statistically significant at $\mathrm{p}<0.05 ; * *$ statistically significant at $\mathrm{p}<0.01$ 